\title{
Reflexiones acerca de los discernimientos para el establecimiento del plazo razonable en el proceso penal
}

\author{
Jorge Isaac Torres Manrique ${ }^{1}$ \\ Investigador externo, Lima, Perú.
}

(Enviado: Febrero, 2016. Aceptado para publicación: Julio, 2016)

\begin{abstract}
Resumen:
La institución jurídica como plazo razonable ha sido tema de deliberación y debate, ya sea con la finalidad de determinarlo, sintonizarlo o defenderlo como para salvaguardar los derechos de los procesados. Y es que el plazo razonable engloba una problemática particular, importante como trascendente, en sus diversas aristas y etapas del proceso, no solamente judicial. En la presente entrega, el autor desarrolla el análisis en relación a la necesaria evaluación de una de las novedades que, vía doctrina jurisprudencial, ofrece recientemente el Tribunal Constitucional peruano. En ese orden de ideas, dicho autor abraza de manera específica, un estudio y reflexión acerca de los criterios de análisis para la determinación del plazo razonable en el proceso penal peruano.
\end{abstract}

Palabras Claves: Plazo razonable; Plazo razonable del proceso penal; Doctrina jurisprudencial comentada.

\begin{abstract}
:
The legal institution as reasonable time limit has been been a cause for deliberation and discussion, whether, in order to determine, tune or defend, as to safeguard the rights of the accused. Reasonable time limit has a problem in itself, important as it is transcendental, in its various facets and stages of the process, not just judicially. In this installment, the author develops the analysis in relation to the necessary assessment of novelty developments that via jurisprudential doctrine, are recently offered by the Peruvian Constitutional Court. In that vein, this author embraces specifically, a study and reflection on criteria analysis for determining the reasonable period in the Peruvian criminal proceedings.
\end{abstract}

Keywords: Reasonable time; Reasonable time limit of criminal proceedings; Jurisprudential doctrine discussed.

\section{Introducción}

Una de las grandes deudas o brechas que tiene la judicatura, así como los demás actores del sistema judicial no solo peruano, termina desnaturalizando la quintaesencia de la justicia procesal penal, la que resulta ser la cuasi quimera de la estricta observancia del fiel respeto al derecho de todo justiciable, a un plazo razonable. Entonces el estudio, desarrollo y debate de la problemática que abraza el plazo razonable, deviene en clamor e interés, de la sociedad democrática en su conjunto. En ese orden de ideas, en la presente

\footnotetext{
${ }^{1}$ Responsable de Coordinación Regional del Programa Presupuestal 0099: Celeridad en los Procesos Judiciales Laborales, del Consejo Ejecutivo del Poder Judicial de la República del Perú. Miembro, Par Académico Evaluador, Corresponsal e Investigador Externo Adscrito al Instituto Vasco de Derecho Procesal (País Vasco). Investigador Externo de la Universidad Tecnológica Centroamericana, UNITEC (Honduras). Colaborador Honorario de Elnotariado.com (Argentina). Colaborador Externo del Bufete Jurídico Internacional, Jordan \& Luciano Abogados (España). Experto en Derecho Empresarial y Administrativo, en Avalón, la Red de Expertos de España, Portugal y Latinoamérica (España). Abogado por la Universidad Católica de Santa María (Perú). Egresado de los Doctorados en Derecho y Administración, y de las Maestrías en Derecho Empresarial y Derecho Penal, por la Universidad Nacional Federico Villarreal (Perú). kimblellmen@ outlook.com.
} 
entrega abordamos el análisis de la resolución del Pleno del Tribunal Constitucional (en adelante TC), Exp. $\mathrm{N}^{\circ}$ 295- 2012-PHC/TC - Caso Aristóteles Román Arce- expedida en fecha $14 / 05 / 15$, la que constituye doctrina jurisprudencial vinculante y versa acerca del establecimiento del cómputo del plazo razonable en el proceso penal.

Así, se tiene que a través de la mencionada sentencia de fondo, el TC ha dispuesto que el cómputo del plazo razonable en el proceso penal debe iniciarse desde la apertura de la investigación preliminar del delito, el cual comprende la investigación policial o la fiscal, y ya no desde la aprehensión del procesado. Asimismo, el TC aclaró que ante la afectación del plazo razonable, la reacción por parte de la justicia constitucional no puede ser la exclusión del procesado, el sobreseimiento o el archivo definitivo del proceso penal. A propósito, cabe dejar constancia que como punto resaltante destaca, que vía la presente resolución sub exámine del $\mathrm{TC}$, el mismo ha introducido un nuevo criterio para el abordamiento de la mencionada empresa. Esto es: la afectación que genera la demora en la situación jurídica de la persona involucrada en el proceso.

Si más preámbulos, iniciemos pues, el presente recorrido por nuestra apreciación de la misma, principalmente en lo relacionado a los criterios de análisis para la determinación del plazo razonable en el proceso penal peruano.

\section{Precisiones sobre de la definición del plazo razonable}

En relación al plazo razonable podemos señalar que este se ha constituido en una garantía para el procesado y el proceso. Asimismo, que se relaciona muy estrechamente con el debido proceso, existiendo entre ellos una correspondencia de especie y género, respectivamente.

Respecto del plazo razonable, tenemos que el Inc. 3., del Art. $139^{\circ}$ de la Constitución Política, establece que: "Son principios y derechos de la función jurisdiccional (...) la observancia del debido proceso y la tutela jurisdiccional”. Además, el plazo razonable ha merecido un sinnúmero de definiciones. Así CORIGLIANO ${ }^{2}$ citando a ZAFARONI / ALIAGA / SLOKAR afirma: "Desde un punto de vista dogmático proceso penal cuya tramitación supera el plazo razonable, esto es de duración excesiva, no solo lesiona el derecho del imputado a ser juzgado rápidamente, sino que también afecta a todos y cada uno de sus derechos fundamentales y sus garantías procesales reconocidas en la Constitución. Como consecuencia, si el proceso se prolonga indebidamente todas sus reglas de funcionamiento acabarán distorsionando su derecho a un juicio rápido y los principios elementales de la actuación legítima del Estado".

\subsection{Interpretacion predominante de la atemporidad del plazo razonable}

Tenemos que dejar constancia que, en relación al plazo razonable de la prisión preventiva o del proceso, fue el Tribunal Europeo de Derechos Humanos (al que denominaremos: TEDH), el que sentó las bases del término "plazo razonable", atribuyéndole al mismo una novísima naturaleza de atemporidad no prevista abstractamente en la ley (denominada por la doctrina por el "no plazo"), sino más bien por el de la indicación que el juzgador

\footnotetext{
${ }^{2}$ CORIGLIANO, Mario E. Plazo razonable y prisión preventiva en la jurisprudencia de la Corte Interamericana de Derechos Humanos. En línea: Recuperado en fecha 15/01/16 de Derecho penal on line http://www.derechopenalonline.com/derecho.php?id=14,535,0,0,1,0, Buenos Aires, p. 01.
} 
evalúe la duración del caso para estimar, a través de diversos criterios, si es que efectivamente se cumplió o no con el plazo razonable. ${ }^{3}$

Cabe señalar que en el caso que lo referido no haya sido probadamente observado, es decir, que el plazo haya devenido en irrazonable - queda solicitar la compensación correspondiente, a efectos de reparar la vulneración del derecho fundamental invocado.

\section{Teoría propugnativa para la determinacion del plazo razonable}

$\mathrm{Al}$ respecto, es de verse que la universalmente aceptada no determinación del plazo en términos de tiempo, en lo concerniente al plazo de naturaleza razonable, no implica la necesaria inexistencia de plausibles propuestas en sentido contrario. Así tenemos:

\subsection{Mandato textual del Orden Jurídico Internacional}

En ese sentido, en defensa de los derechos fundamentales procesales, se postula que el plazo razonable bien tendría que ser establecido específicamente en plazos preclusorios, en mérito a disposición expresa del ordenamiento jurídico internacional.

Así tenemos, que PASTOR ${ }^{4}$ afirma ${ }^{5}$ : "Los tratados internacionales que establecen derechos fundamentales, deben ser vistos como modelos para las regulaciones del derecho interno de los EE. MM. (...). Así, la nómina de derechos procesales de los distintos tratados debe servir de marco para la redacción de normas procesales, claras y precisas, que den vida y protección (efectividad) a los derechos consagrados abstractamente en ellos (...). Esa tarea constituye el contenido de la obligación de los Estados que forman parte de los convenios. En el plano internacional, la función de los órganos de control de los tratados será confrontar las regulaciones nacionales de los derechos convencionales para determinar si satisfacen las pretensiones de un derecho fundamental (control de razonabilidad) o si son insuficientes para asegurar su vigencia plena (función de garantía de los derechos fundamentales)".

\subsection{Mandato expreso del principio del Estado de Derecho}

El mismo autor sostiene que, en predios de determinación temporal efectiva del plazo razonable, la interpretación de la judicatura debe quedar postergada a favor del legislador. En ese orden de ideas acota: "En cuanto al problema de la excesiva duración del proceso penal, el esquema anteriormente expuesto determina que ni el límite máximo de prolongación de un proceso (plazo razonable) ni las consecuencias jurídicas de sobrepasarlo pueden ser definidos por la ley de un modo abierto, ni dejados a la determinación de los jueces (teoría del concepto jurídico indeterminado), sino que deben ser establecidos por el Parlamento para que realmente rija en toda su extensión el

\footnotetext{
3 TORRES MANRIQUE, Jorge Isaac. A propósito del precedente vinculante del plazo razonable de la detención judicial preventiva, STC No 3771-2004-HC. En línea: Recuperado en fecha 15/01/16 de la Universidad de Fribourg http://perso.unifr.ch/derechopenal/assets/files/articulos/a_20121108_01.pdf, Fribourg, p. 03.

${ }^{4}$ PASTOR, Daniel R. Acerca del derecho fundamental al plazo razonable de duración del proceso penal. En línea: Recuperado en fecha 15/01/16 de Revista de estudios de la justicia.

http://www.derecho.uchile.cl/cej/recej/recej4/archivos/Articulo\%20sobre\%20plazo\%20razonable\%20Past or_10_.pdf, Chile, 2004, p. 61.

${ }^{5}$ Cabe dejar constancia que el mencionado autor, Daniel Pastor, esboza y desarrolla de manera solvente además, otras propuestas o argumentos, verbi gratia: i) Del principio nulla coactio sine lege, ii) Del principio de legalidad material, iii) De la división de poderes, y iv) De las conclusiones intermedias.
} 
principio político según el cual toda la actividad del Estado, pero especialmente la que entraña el ejercicio de su violencia punitiva, tenga su legitimación en la ley y encuentre sus límites en ella, incluso temporales.

En el régimen procesal penal de un estado de derecho, la ley es la única fuente de sus normas. Así pues, el plazo razonable debe ser fijado por la ley y no por los tribunales, ya que para el orden jurídico-político de un estado constitucional de derecho resulta inaceptable el derecho judicial e incluso penalmente desaprobado en el caso de decisiones contra legem (delito de prevaricación)". ${ }^{6}$

\section{Influencia del Tribunal Europeo de Derechos Humanos al cómputo del plazo razonable en los predios del proceso penal}

Es preciso dejar constancia, que la garantía internacional de los derechos humanos por excelencia, se constituye en algo cada vez más necesario. Ergo, es de verse que el Tribunal Europeo de Derechos Humanos (TEDH) — conocido también: Tribunal de Estrasburgo y Corte Europea de Derechos Humanos - conjuntamente con la Corte Interamericana de Derechos Humanos, se constituyen en el mecanismo más avanzado que existe en el orbe. He ahí su especial importancia, aporte y trascendencia.

Entonces podemos señalar que el patrimonio jurisprudencial del TEDH, cuyo señorío ostenta auténticos como reveladores "leading cases", ha influido primordialmente: (i) Proporcionando algunos de sus criterios e ideas esenciales en su jurisprudencia, muy saludables como significativos en muchos tribunales constitucionales y supremos - no solamente de los Estados miembros de la Eurozona-, en razón a que los mismos han sido adoptados. Y (ii) Siendo modelo y señero referente para otros sistemas de protección internacional de derechos en otros ámbitos geográficos, contribuyendo al desarrollo y fortalecimiento de un derecho internacional de los derechos humanos. ${ }^{7}$

Así, tenemos que el plazo razonable en el proceso penal (proveniente del Sistema Europeo de Protección de Derechos Humanos, posteriormente acogido por el Sistema Interamericano de Protección de Derechos Humanos y por el Tribunal Constitucional peruano), se encuentra implícitamente inmerso en el derecho al debido proceso regular.

En ese orden de ideas, específicamente podemos precisar que dichos criterios aportados por el TEDH, se plasman en las sentencias de fechas 13/07/83 y 07/07/89. En la primera, por el caso Zimmermann y Steiner contra Suiza (demanda $N^{\circ} 8737 / 1979$ ), la que en resumidos términos se basa en que un grupo de ciudadanos suizos demandan a Suiza por las dilaciones indebidas que tuvieron lugar en el marco de un procedimiento judicial de un recurso administrativo, donde la duración del proceso no responde a las exigencias del plazo razonable. En la segunda, por el caso Unión Alimentaria Sanders S.A. contra España ( $\mathrm{N}^{\circ}$ 11681/1985), la que resuelve la demanda interpuesta por una sociedad española contra España, por la existencia de dilaciones indebidas en el proceso civil de reclamación de cantidad en el que estaba incursa y en la que no existían circunstancias excepcionales que justificasen la pasividad de los tribunales.

\footnotetext{
${ }^{6}$ PASTOR, Daniel R. Ob. cit., p. 64.
} 
Así también, conviene referir los criterios establecidos para determinar el desarrollo de un plazo razonable: fueron dados por el Tribunal Europeo de Derechos Humanos (TEDH) y también compartidos por el Sistema Interamericano de Protección de Derechos Humanos y Tribunal Constitucional peruano, a saber: i) La complejidad del caso, ii) Comportamiento del procesado, y iii) La manera en que fue llevado por las autoridades judiciales. De dicho modo, es de verse que así lo reconoce y recoge la Corte Interamericana de Derechos Humanos (CIDH) en sus tres emblemáticos casos: i) Caso Genie Lacayo vs. Nicaragua, párr. $77^{7}$, ii) Caso Bayarri vs. Argentina, ${ }^{8}$ supra nota 13, párr. 107, y iii) Caso Heliodoro Portugal vs. Panamá, ${ }^{9}$ supra nota 13, párr. 149.

\section{Análisis de los criterios para la determinacion de la razonabilidad del plazo en el proceso penal de la resolucion Sub Exámine}

A los criterios señalados previamente, el TC agregó: iv) La afectación que genera la demora en la situación jurídica de la persona involucrada en el proceso - la misma que fue tomada del desarrollo inicial llevado a cabo por la CIDH, en el caso Valle Jaramillo y otros vs. Colombia - En ese orden de ideas, procederemos a analizarlos:

\subsection{La complejidad del asunto}

En este punto, la resolución del TC bajo comentario, refiere: "En el que se consideran factores tales como la naturaleza y gravedad del delito, los hechos investigados, los alcances de la actividad probatoria para el esclarecimiento de los hechos, la pluralidad de agraviados o inculpados, o algún otro elemento que permita concluir, con un alto grado de objetividad, que la dilucidación de un determinado asunto resulta particularmente complicada y difícil”.

Por otro lado, la CIDH enseña: "La complejidad del asunto se determina por una serie de factores de iure y de facto del caso concreto. Así, en el proceso penal, aunque no exhaustivamente, dichos factores pueden estar referidos a:

a) El establecimiento y esclarecimiento de los hechos, los cuales pueden ser simples o complejos

b) El análisis jurídico de los hechos acerca de los cuales se ha producido el proceso penal

c) La prueba de los hechos, la cual puede ser difícil, necesariamente prolongada o de complicada actuación

d) La pluralidad de agraviados o inculpados; entre otros factores". ${ }^{10}$

\footnotetext{
${ }^{7}$ Sentencia de la Corte IDH. En línea: Recuperada en fecha 15/01/16 de http://www.corteidh.or.cr/docs /casos/articulos/seriec_30_esp.pdf.

${ }^{8}$ Sentencia de la Corte IDH. En línea: Recuperada en fecha 15/01/16 de http://www.tc.gob.pe/portal/ servicios/sentenciascidh/seriec_187_esp.pdf.

${ }^{9}$ Sentencia de la Corte IDH. En línea: Recuperada en fecha 15/01/16 de http://www.corteidh.or.cr/docs/ casos/articulos/seriec_186_esp.pdf.

${ }^{10}$ VITERI CUSTODIO, Daniela Damaris. El derecho al plazo razonable en el proceso penal: el desarrollo jurisprudencial de la Corte Interamericana de Derechos Humanos y del Tribunal Constitucional peruano. En línea: Recuperado en fecha 15/01/16 de http://www2.congreso.gob.pe/sicr/cendocbib/con4_uibd.nsf/6E1AF1F197B5442B05257A880019DF6B/\$ FILE/104300574-El-Plazo-Razonable.pdf, Lima, s/a, pp. 03- 04.
} 
A propósito de los otros factores, para determinar la complejidad del asunto, que refiere la parte final del párrafo anterior, cabe citar algunos: i) El párrafo 81, de la sentencia de fecha 29/01/97, del caso Genie Lacayo vs. Nicaragua, ${ }^{11}$ de la CIDH, refiere que la Corte Europea ha empleado para determinar la razonabilidad del plazo en el conjunto de su trámite, lo que llama "análisis global del procedimiento". ii) El párrafo 57, de la sentencia de fecha 28/11/02, del caso Cantos vs. Argentina, ${ }^{12}$ de la mencionada judicatura, menciona que la otra cuestión debatida en estas actuaciones respecto del proceso seguido, es si el procedimiento se ha ajustado a los artículos 8 y 25 de la Convención Americana en cuanto garantizan el derecho a una respuesta de la autoridad judicial dentro de un plazo razonable. iii) El párrafo 153, de la sentencia de fecha 31/08/04, del caso Ricardo Canese vs. Paraguay, ${ }^{13}$ del referido tribunal, sostiene que las pruebas a ser aportadas al proceso, $\Theta$ a la cantidad de testigos, o la cantidad de víctimas sean de un número muy elevado.

Por otro lado, advertimos que para determinar la complejidad de un caso, si bien es cierto que el TC lo asume desde una óptica más genérica, en su turno la CIDH aterriza de manera más específica. En la resolución materia de reflexión únicamente se hace referencia a que "el juez no ha fundamentado la dilación por una especial dificultad del proceso que lo derive en complejo". En ese sentido, es de verse que lo afirmado por el TC no pasa solamente por el tema de que la judicatura ordinaria correspondiente tenga que fundamentar suficientemente el porqué de una abordamiento al proceso, como complejo, digamos de facto; ello en razón a que bien pudo llevarlo a cabo dicho colegiado constitucional.

\subsection{La actividad o conducta procesal del interesado}

En la presente resolución, el TC indica: "en el que se evalúa si su actitud ha sido ardiligente o ha causado retrasos o demoras en el proceso, por cuanto si la dilación ha sido provocada por él, no cabe calificarla de indebida. En ese sentido, habrá que distinguir entre el uso regular de los medios procesales que la ley prevé y la actitud obstruccionista o la falta de cooperación del interesado, la cual estaría materializada en la interposición de recursos que desde su origen y de manera manifiesta se encontraban condenados a la desestimación. En todo caso, corresponde al juez demostrar la conducta obstruccionista del interesado".

En resumidos términos, de lo que se trata es determinar si el interesado obró con temeridad o mala fe procesales. Así, se aprecia que la resolución del TC en comentario, indica: "De la simple constatación de las fechas se advierte que existe dilación en el trámite del proceso penal cuestionado, demora que este tribunal considera que no es atribuible a Aristóteles Román Arce Páucar (...)”. Por consiguiente se tiene que lo esbozado por el TC queda corto, en tanto se limita a afirmar que existe dilación, pero sin argumentar debidamente cómo es que el interesado no incurrió en temeridad o mala fe procesales.

\footnotetext{
${ }^{11}$ Sentencia de la Corte IDH. En línea: Recuperada en fecha 15/01/16 de http://www.corteidh.or.cr/docs/casos/articulos/seriec_30_esp.pdf.

${ }^{12}$ Sentencia de la Corte IDH. En línea: Recuperada en fecha 15/01/16 de http://www.corteidh.or.cr/docs/casos/articulos/seriec_97_esp.pdf.

${ }^{13}$ Sentencia de la Corte IDH. En línea: Recuperada en fecha 15/01/16 de http://www.corteidh.or.cr/docs/casos/articulos/seriec_111_esp.pdf.
} 


\subsection{La conducta de las autoridades judiciales}

Respecto de este punto en la resolución bajo evaluación, el TC sostiene: “donde se evalúa el grado de celeridad con el que se ha tramitado el proceso, sin perder de vista en ningún momento el especial celo que es exigible a todo juez encargado de dilucidar una causa. Para ello, será preciso examinar las actuaciones u omisiones de los órganos judiciales en la tramitación de la causa. Las indebidas e injustificadas acumulaciones o desacumulaciones de procesos; la suspensión reiterada e injustificada del juicio oral; la admisión y/o la actuación de una prueba manifiestamente impertinente; la reiterada e indebida anulación por parte del órgano jurisdiccional de segundo grado respecto de las decisiones del órgano jurisdiccional de primer grado, etc., vienen a ser ejemplos de lo primero. La inobservancia injustificada de los horarios para la realización de las diligencias; la demora en la tramitación y resolución de los medios impugnatorios, etc., vienen a ser ejemplos de lo segundo".

Por su parte precisamos traer a colación lo señalado por la jurisprudencia del TC, en el caso Salazar Monroe (EXP. N 05350-2009-PHC/TC), en la que respecto de lo propio, en su Fundamento 26, preconiza: "Para evaluar la conducta o comportamiento de las autoridades judiciales es necesario tener presente:

a) La insuficiencia o escasez de los tribunales

b) La complejidad del régimen procesal

c) Si los actos procesales realizados han contribuido o no a la pronta resolución del proceso penal".

Observamos nuevamente diferencias en el desarrollo de las resoluciones del TC, respecto de la conducta de las autoridades judiciales. Las mismas radican esencialmente en que mientras por un lado la presente resolución materia de examen, lo hace de manera más detallada, por otro la correspondiente al EXP. N 05350-2009-PHC/TC lo hace de manera más bien genérica y esquemática.

Al ocuparnos acerca de lo analizado por el TC en la presente resolución in comento, apreciamos que indica: "Si bien los magistrados emplazados, en sus declaraciones arguyen que los medios de defensa presentados por el recurrente han contribuido a la dilación del proceso, en autos no se aprecia algún apercibimiento que el juez hubiese decretado contra el recurrente por una conducta renuente a las citaciones del juzgado o que los medios de defensa presentados - conforme al derecho de defensa que le asiste a todo procesado - hayan sido considerados como maliciosos. Asimismo a la fecha no obra en autos algún documento que acredite si se ha determinado definitivamente la situación jurídica del recurrente".

Entonces de lo señalado se colige que la conducta de las autoridades judiciales devino en temeridad procesal, en perjuicio del procesado. A propósito, se tiene que litigar con temeridad o accionar así en el juicio es la defensa sin fundamento jurídico. Es la conducta de quien sabe o debe saber que carece de razón y/o falta de motivos para deducir o resistir la pretensión, no obstante así lo hace, abusando de la jurisdicción o resiste la pretensión del contrario. ${ }^{14}$

\footnotetext{
${ }^{14}$ TORRES MANRIQUE, Jorge Isaac. Temeridad y malicia procesales al banquillo: crónica de dos lacras
} jurídicas que pretenden consolidarse. En línea: Recuperado en fecha 15/01/16 de la Academia Brasileira 


\subsection{La afectación que genera la demora en la situación jurídica de la persona involucrada en el proceso}

Acerca del presente acápite, tenemos que fue desarrollado inicialmente por la CIDH, vía el Caso Valle Jaramillo y otros vs. Colombia (sentencia de fecha 27/11/08). Así, se tiene que dicha Corte agregó un criterio - el cuarto para nuestro TC - para el análisis para la determinación del plazo razonable en el proceso penal, a los ya establecidos por el Tribunal Europeo de Derechos Humanos.

Respecto al cuarto criterio agregado, la mencionada resolución, el Alto Tribunal Interamericano, en su Fundamento 155 establece: "La Corte ha establecido que es preciso tomar en cuenta tres elementos para determinar la razonabilidad del plazo: a) la complejidad del asunto, b) la actividad procesal del interesado, y c) la conducta de las autoridades judiciales. El tribunal considera pertinente precisar además que en dicho análisis de razonabilidad se debe tomar en cuenta la afectación generada por la duración del procedimiento en la situación jurídica de la persona involucrada en el mismo, considerando, entre otros elementos, la materia objeto de controversia. Si el paso del tiempo incide de manera relevante en la situación jurídica del individuo, resultará necesario que el procedimiento corra con más diligencia a fin de que el caso se resuelva en un tiempo breve".

Por su parte, en la resolución materia del presente trabajo, se tiene que el TC lo aborda pero esencialmente en relación a la necesidad de reparación in natura por parte de los órganos jurisdiccionales. Así, señala: “(...) la misma que consiste en emitir el pronunciamiento definitivo sobre el fondo del asunto en el plazo más breve posible”. Sin embargo el TC olvida que la reparación debida y oportuna al procesado, a consecuencia de la dilación acontecida en dicho proceso penal, no pasa únicamente por dicha consideración. Allí quedó evidenciada la naturaleza muy limitada de su pronunciamiento.

\section{Síntesis de la resolución del TC}

La misma corresponde al Exp. $\mathrm{N}^{\circ}$ 295- 2012-PHC/TC, que fue expedida en fecha 14/05/15 (la misma como señalamos ab initio, constituye doctrina jurisprudencial vinculante, en razón a que seis fundamentos de la misma fueron declarados constitutivos de dicha naturaleza), y que versa acerca de un recurso de agravio constitucional, interpuesto contra la sentencia de fecha 05/10/11, expedida por la Primera Sala Penal para Procesos con Reos Libres de la Corte Superior de Justicia de Lima, la que revocó la sentencia que declaró fundada la demanda y reformándola, declaró improcedente dicha demanda.

Así, en principio se tiene que en fecha 16/02/11 se interpone una demanda de habeas corpus contra los jueces de la Tercera Sala Penal de la Corte Superior de Justicia del Callao, alegando la vulneración a sus derechos a ser juzgado dentro de un plazo razonable y a la libertad personal, en el proceso penal que se le sigue, por la presunta comisión del

de Direito Processual Civil http://www.abdpc.org.br/abdpc/artigos/JORGE\%20ISAAC\%20TORRES\%20MANRIQUE\%20\%20$\%$ 20ENSAYO\%20TEMERIDAD\%20PROCESAL.pdf, Porto Alegre, p. 09. 
delito de usurpación agravada, en perjuicio de la Compañía Constructora e Inmobiliaria Bacilio López S.A. y otros.

Agrega el demandante que el proceso penal iniciado en fecha 06/04/06, viene siendo ha sido dilatado por el denunciante, vía diversas argucias legales. Incluso también lo propio, respecto de los jueces demandados, en vista a que pese a haberse vencido el plazo de investigación del proceso, y a haber sido absuelto hasta en dos oportunidades, la Sala Superior demanda anuló los actuados y ordenó la ampliación del plazo investigatorio, sin que medie motivo alguno, con la finalidad que se le continúe investigando.

Acota también que a través de la resolución de fecha 22/09/10, la Sala Superior emplazada anuló la sentencia absolutoria, en razón a que supuestamente se había cometido un error de tipificación del hecho delictivo, respecto del cual las partes no se habrían defendido. Señalando, que ello deviene en absurdo, en tanto que el único que corresponde defenderse resulta ser el imputado y que éste había sido absuelto. Además refiere que no se habría motivado debidamente la resolución de la excepción de naturaleza de acción, constituyéndose nuevamente el imputado, en el único afectado.

A continuación indica que es el denunciado quien se constituye en el único procesado y que se investiga un solo delito, por lo que dicho proceso no puede ser calificado como complejo y que sin embargo, han transcurrido más de cinco años sin que exista decisión definitiva que resuelva su situación jurídica, lo cual vulnera sus derechos a ser juzgado dentro de un plazo razonable y a la libertad personal. Por su parte, el Procurador Público del poder Judicial contesta la demanda y solicita que la misma sea declarada improcedente, pues considera que la Sala emplazada ha observado las garantías inherentes al debido proceso, ya que ante la existencia de vicios o defectos en la tramitación del cuestionado proceso, ordenó la nulidad de las resoluciones emitidas, disponiendo la ampliación de la investigación.

En su turno, el demandante reitera los extremos de la demanda y enfatiza que el proceso penal seguido en su contra corresponde a uno sumario y que sin embargo han transcurrido seis años desde su inicio sin que a la fecha exista sentencia definitiva. A su vez, los magistrados emplazados afirman que en el proceso penal en cuestión el demandante ha deducido e impulsado una serie de medios de defensa, contribuyendo así a que los plazos del proceso se dilaten, más aun cuando dichos medios han sido declarados infundados y/o improcedentes. Adicionan que la resolución cuestionada ha sido dictada conforme a ley.

Continuando con la secuencia del devenir procesal del presente caso, se tiene que en fecha 18/07/11, el Décimo Primer Juzgado Penal de Lima declaró fundada la demanda y declaró nula la resolución de fecha 22/12/10. Además ordenó que la Sala Superior emplazada en el plazo de treinta días, emita sentencia que defina la situación jurídica del demandante, por considerar que han transcurrido más de cinco años desde que se inició el proceso penal, pese a que se investiga un solo delito contra un solo imputado, sin que exista el control de los plazos por parte del juez y que el demandante no ha tenido una actuación obstruccionista. Luego que no se motivó los hechos, no fueron debidamente investigados y que determinaron la ampliación de la instrucción por un plazo adicional.

Seguidamente, la Primera Sala Penal para Procesos con Reos Libres de la Corte Superior de Justicia de Lima revocó la sentencia apelada y en la reforma declaró improcedente la 
demanda, por considerar que la dilación del proceso penal no puede ser atribuida a los jueces emplazados, luego que el Ministerio Público fue quien solicitó que se actuaran otras pruebas a fin de que no se afecte el derecho de defensa de las partes procesales.

Finalmente el TC vía resolución de fecha 03/05/12 y sobre la base del principio de economía procesal, considera que el titular del Segundo Juzgado Penal Transitorio del Callao también participó en la tramitación del proceso penal en cuestión, optó por una medida alternativa y excepcional. Además, porque previo a emitir pronunciamiento que ponga fin a la controversia, le notificó el recurso de agravio constitucional al referido juez, otorgándole cinco días hábiles para que ejerza su derecho de defensa. Así, la citada resolución fue notificada en fecha 17/09/12 sin que se haya remitido respuesta alguna.

En consecuencia, dicho colegiado constitucional declaró fundada la demanda en lo referido a la afectación del derecho a ser juzgado dentro de un plazo razonable. Ordenó a la Tercera Sala Penal de la Corte de Justicia del Callao que en el plazo de quince días naturales, contados desde la fecha de notificación de dicha resolución, emita y notifique la correspondiente sentencia por la que decida finalmente la situación jurídica del sujeto procesado por la presunta comisión del delito de usurpación agravada (Exp. $\mathrm{N}^{\circ}$ 6142006).

Además dispuso poner en conocimiento de la mencionada resolución de la Oficina de Control de la Magistratura, a efectos de que investigue el comportamiento del juez del Segundo Juzgado Penal Transitorio y de los magistrados de la Tercera Sala Penal de la Corte Superior de Justicia del Callao, por la excesiva dilación en la tramitación del proceso penal.

\section{Análisis de la resolución in comento}

En principio, señalar que por un lado, maravilla que el TC se haya esmerado en la descripción, significancia, incluso de manera esquemática cuando desarrolla lo concerniente a cada uno de los tres primeros criterios, a saber: i) La complejidad del caso, ii) El comportamiento del procesado, y iii) La manera en que fue llevado por las autoridades y judiciales. Tal y como se puede apreciar en el Fundamento 4 de la delimitación del petitorio, de la resolución materia del presente trabajo. Por otro lado, se tiene respecto del cuarto criterio (la afectación que genera la demora en la situación jurídica de la persona involucrada en el proceso), olvidó la prolijidad puesta de manifiesto para con los tres primeros criterios.

Mención aparte merece la muy escasa fundamentación que ofrece el TC en la señalada resolución, para analizar la aplicación de cada uno de los criterios mencionados. Habría sido muy interesante que para lo cual, se hubiera observado similar correspondencia de plasmación; tal y como si se aprecia, hasta con saludable colmación motivacional, en lo asumido y desarrollado por el TEDH, en las mencionadas sentencias de los casos: Zimmermann y Steiner contra Suiza (demanda $N^{\circ}$ 8737/1979) y Unión Alimentaria Sanders S.A. contra España (demanda $\left.\mathrm{N}^{\circ} 11681 / 1985\right) .{ }^{15}$

A modo a retroalimentación, cabe reflexionar acerca de la real utilidad de la implantación del referido cuarto criterio ("La afectación que genera la demora en la situación jurídica

${ }^{15}$ DÍAZ REVORIO, Francisco Javier. Ob. cit., pp. 489- 492 y 619- 622. 
de la persona involucrada en el proceso"). Entonces: ¿Cuál es el balance de la aplicación de este criterio en la jurisprudencia de la CIDH? Resulta que si bien este criterio ha sido constantemente señalado en su jurisprudencia, no ha sido de aplicación para resolver los casos, con excepción (incluida la resolución in comento), del caso donde se pronunció sobre la materia - caso de la Comunidad Indígena Xákmok Kásek vs. Paraguay (de fecha 24/08/10) - haciendo uso de este parámetro de examen para ponderar el paso del tiempo en la calidad de vida de los procesados en donde estableció que la demora en la obtención de una solución definitiva al problema de la tierra de los miembros de la Comunidad ha incidido directamente en su estado de vida. ${ }^{16}$

En ese sentido, tal y como acabamos de indicar en la presente resolución bajo revisión, a efectos de determinar la vulneración del plazo razonable en dicho proceso penal, el TC hace uso del cuarto criterio mencionado. En ese extremo, respecto de la tratativa a la afectación que genera la demora en la situación jurídica de la persona involucrada en dicho proceso, en cierta forma deja en desamparo al procesado.

Cabe agregar que la disposición de la mencionada resolución sea puesta de conocimiento de la Oficina de Control de la Magistratura (OCMA), con la finalidad que se investigue el comportamiento, tanto de del juez del Segundo Juzgado Penal Transitorio y de los magistrados de la Tercera Sala Penal de la Corte Superior de Justicia del Callao, por la excesiva dilación en la tramitación del proceso penal, Expediente N. ${ }^{\circ}$ 614-2006; no soluciona o atiende en extremo alguno lo concerniente a la total o completa afectación que genera la demora en la situación jurídica de la persona involucrada en el proceso baja análisis. Consecuentemente, postulamos porque el TC debió haber llevado a cabo lo propio respecto al cuarto criterio.

Dicho sea de paso, llama la atención, por decir lo menos, que el TC, en la resolución bajo comentario, indique en su Fundamento 14: "De la simple constatación de las fechas se advierte que existe dilación en el trámite del proceso penal cuestionado (...)". Sin embargo en el Fundamento 3, de la parte resolutiva, afirma: "Poner la presente sentencia en conocimiento de la Oficina de Control de la Magistratura (...) por la excesiva dilación en la tramitación del proceso penal (...)". Así, se advierte que el TC en un primer momento dice encontrar la existencia de dilación, pero luego sin haber fundamentado su cambio de opinión, señala que hubo excesiva dilación.

Y si los magistrados citados incurrieron en temeridad procesal, no se encuentra explicación por la no aplicación de la multa correspondiente que debió imponerles el TC, tal y como lo prescribe el código procesal madre, (Código Procesal Civil, CPC), el mismo que se aplica supletoriamente a todo lo normado por sus pares procesales en el presente al Código Procesal Constitucional (CPConst.) —es de verse lo preceptuado por la Primera Disposición Final del CPC, la que enseña: "Las disposiciones de este Código se aplican supletoriamente a los demás ordenamientos procesales, siempre que sean compatibles con su naturaleza"- También amerita precisar que los sujetos del proceso que incurren en

\footnotetext{
${ }^{16}$ ESPINOZA RAMOS, Benji Gregory. La "afectación generada por la duración del procedimiento en la situación jurídica del procesado" como cuarto criterio de análisis en la violación del derecho a ser juzgado dentro de un plazo razonable: una mirada desde la jurisprudencia de la Corte Interamericana de Derechos Humanos. En línea: Recuperado en fecha 15/01/16 de Alvarezyralaabogados.com http://alvarezyralaabogados.com/abogados/docs/articulos/bespinozar/Plazo\%20razonable.pdf, Lima, pp. $10-11$.
} 
temeridad o malicia procesales, son pasibles de sanciones como la multa. Así, el Inc. 1, $a b$ initio, del Art. 53.-, del CPC, que trata sobre las facultades coercitivas del juez y que en mérito a ellas puede "imponer multa compulsiva y progresiva destinada a que la parte o quien corresponda, cumpla sus mandatos con arreglo al contenido de su decisión”.

Por otro lado, consideramos ser contestes respecto del acrecentamiento del número de criterios para la determinación de la razonabilidad del plazo en el proceso penal, lo que debe importar es la aplicación de los criterios que resulten precisos a cada caso en particular, en lugar de pretender aplicar la totalidad de criterios a todos los casos por igual.

\section{Conclusión}

Sugerimos que los esfuerzos de avance no solo devengan enfilados a perfeccionar la metodología y aplicación o creación de nuevos criterios para el análisis y determinación del plazo razonable en el proceso penal peruano, si no que lo propio debería ser de especial preocupación, para lo relacionado a la aplicación de dichos criterios, respecto a su debida fundamentación.

Empero, consideramos que el desvelo y reto principal debiera ser que una vez determinado el eventual menoscabo del plazo razonable, se aterrice con mayor razón y de manera memorable, legítima o justa, en los predios de resarcimiento y reparación del procesado. Esto último en tanto advertimos que este procesado parece ser finalmente dejado de lado, olvidado, extraviado, condenado a su suerte, a la ignominia, asegurándole el seguro camino hacia su revictimización.

A mayor abundamiento, la explicación de la lógica mencionada también radica en razón a que en la correspondiente empresa de descifrar vulneración de la razonabilidad o no del plazo procesal penal, aparecen también conjugados de manera indisoluble los derechos inherentes, tales como a la legalidad, legitimidad, debido proceso, entre otros. Ergo, los mismos precisan ser debidamente salvaguardados. Entonces dicha empresa se torna particular cuidado y de dimensiones mayúsculas, lo que implica la obligada respuesta jurisdiccional en los mismos términos y extremos.

Cabe precisar así como nuevamente resaltar el señero, estimulante, disruptivo, como muy notorio avance - equiparado debidamente, en el rigor de fondo y forma- de la jurisprudencia del TEDH y de la CIDH, en ese orden; huelga dejar constancia que amerita preponderar el esfuerzo paulatino de la analizada doctrina jurisprudencial del TC (Exp. $\mathrm{N}^{\circ}$ 295- 2012-PHC/TC, caso Aristóteles Román Arce). Se torna innegablemente saludable en términos de la tan aspirada -y pocas veces alcanzada- quinta esencia del derecho, no solamente en el escenario procesal penal.

En ese sentido, hacemos votos a efectos que dicho florecimiento sea firme y sólido, es decir, no termine siendo objeto de eventuales marchas y contramarchas. Ello no solo en beneficio de la totalidad de actores del proceso penal, si no en defensa del fortalecimiento de la juridicidad y consolidación del sistema jurídico imperante, caracterizado por el Estado Constitucional de Derecho, Derecho Procesal Garantista y una correcta como equitativa administración de justicia.

Aunque, deviene en obvio, que la doctrina jurisprudencial del TC analizada, abraza otras novedades y aportes (las mismas que hemos hecho referencia en la parte introductoria del 
presente desarrollo). Sin embargo dejamos constancia que cuasi de manera exclusiva, en lo que a nuestro trabajo compete, creemos haber asumido al menos en parte, el compromiso de reflexionar acerca de los criterios de análisis para la determinación del plazo razonable.

Y es que finalmente a mayor abundamiento, debemos tomar nota que en estos tiempos de nada auspiciosa coyuntura y especial trascendencia de novedosa vigencia del nuevo código procesal penal, de la cada vez asfixiante criminalidad organizada, inseguridad ciudadana, rebrote de corrupción, desinstitucionalización y arribo a la digamos, Cuarta $\mathrm{Ola}^{17}$, la respuesta de la judicatura principalmente tiene que estar muy a tono. Ese se constituye en otro ineludible como insoslayable gran reto. Asumámoslo como corresponde.

\section{Bibliografía}

CORIGLIANO, Mario E. Plazo razonable y prisión preventiva en la jurisprudencia de la Corte Interamericana de Derechos Humanos. En línea: Recuperado en fecha 15/01/16 de Derecho penal on line http://www.derechopenalonline.com/derecho. php?id=14,535,0,0,1,0, Buenos Aires.

DIAZ REVORIO, Francisco Javier. (2004). El Tribunal Europeo de Derechos Humanos: Significado y trascendencia. En: Jurisprudencia del Tribunal Europeo de Derechos Humanos. DIAZ REVORIO, F. J. (Compilador). Palestra Editores. Lima.

ESPINOZA RAMOS, Benji Gregory. La "afectación generada por la duración del procedimiento en la situación jurídica del procesado" como cuarto criterio de análisis en la violación del derecho a ser juzgado dentro de un plazo razonable: una mirada desde la jurisprudencia de la Corte Interamericana de Derechos Humanos. En línea: Recuperado en fecha 15/01/16 de Alvarezyralaabogados.com http://alvarezyralaabogados.com/abogados/docs/articulos/bespinozar/Plazo\%20ra zonable.pdf, Lima.

GARRIDO KOECHLIN, Juan José. La cuarta ola. En línea: Recuperado en fecha 15/01/16, de Diario Peru21 http://peru21.pe/opinion/juan-jose-garrido-cuarta-ola2217995.

PASTOR, Daniel R. Acerca del derecho fundamental al plazo razonable de duración del proceso penal. En línea: Recuperado en fecha 15/01/16 de Revista de estudios de la justicia. http://www.derecho.uchile.cl/cej/recej/recej4/archivos/Articulo\%20sobre \%20plazo\%20razonable\%20Pastor_10_.pdf, Chile, 2004.

TORRES MANRIQUE, Jorge Isaac. A propósito del precedente vinculante del plazo razonable de la detención judicial preventiva, STC N 3771-2004-HC. En línea: Recuperado en fecha 15/01/16 de la Universidad de Fribourg http://perso.unifr.ch/ derechopenal/assets/files/articulos/a_20121108_01.pdf, Fribourg.

TORRES MANRIQUE, Jorge Isaac. Temeridad y malicia procesales al banquillo: crónica de dos lacras jurídicas que pretenden consolidarse. En línea: Recuperado en fecha 15/01/16 de la Academia Brasileira de Direito Processual Civil

\footnotetext{
${ }^{17}$ GARRIDO KOECHLIN, Juan José. La cuarta ola. En línea: Recuperado en fecha 15/01/16, de Diario Peru21 http://peru21.pe/opinion/juan-jose-garrido-cuarta-ola-2217995, Lima.
} 
http://www.abdpc.org.br/abdpc/artigos/jorge\%20isaac\%20torres\%20manrique $\% 2$ 0\%20-\%20ensayo\%20temeridad\%20procesal.pdf, Porto Alegre.

VITERI CUSTODIO, Daniela Damaris. El derecho al plazo razonable en el proceso penal: el desarrollo jurisprudencial de la Corte Interamericana de Derechos Humanos y del Tribunal Constitucional peruano. En línea: Recuperado en fecha 15/01/16 de http://www2.congreso.gob.pe/sicr/cendocbib/con4_uibd.nsf/6e1af1f1 97b5442b05257a880019df6b/\$file/104300574-el-plazo-razonable.pdf, Lima.
"LA REVISTA INNOVARE NO SE HACE RESPONSABLE EN NINGÚN CASO DE LOS CONTENIDOS, DATOS, CONCLUSIONES U OPINIONES VERTIDAS EN LOS ARTÍCULOS PUBLICADOS, SIENDO ESTA RESPONSABILIDAD EXCLUSIVA DEL (DE LOS) AUTOR (AUTORES)" 